\title{
Tracking Sustainability Targets with Quantitative Indicator Systems for Performance Measurement of Industrial Symbiosis in Industrial Parks
}

\author{
Anna Lütje ${ }^{1,2, *}$ and Volker Wohlgemuth ${ }^{2}$ \\ 1 Institute of Environmental Communication, Leuphana University Lüneburg, Universitätsallee 1, \\ 21335 Lüneburg, Germany \\ 2 School of Engineering-Technology and Life, HTW Berlin University of Applied Sciences, Treskowallee 8, \\ 10318 Berlin, Germany; volker.wohlgemuth@htw-berlin.de \\ * Correspondence: anna.luetje@htw-berlin.de
}

Received: 10 December 2019; Accepted: 3 January 2020; Published: 8 January 2020

\begin{abstract}
Industrial Symbiosis (IS) is a systematic and collective (business) approach to optimizing the use of materials and energy among cross-sectoral industries in order to initiate and exhaust extended cascading systems; it is associated with (synergistic) environmental, technical, social, and economic benefits. For monitoring and controlling the development and progress of an IS system, an indicator system must be set up to standardize and assess the IS (sustainability) performance. This study aims to present a quantitative indicator system to enable the tracking of set sustainability targets of an IS system in Industrial Parks (IPs) for goal-directed IS management. The presented guiding framework encourages IP members in IS systems to set sustainability objectives and to evaluate and track their performance over time with a quantitative indicator system. In particular, established and (partly) internationally standardized methods-such as Material Flow Analysis (MFA), Material Flow Cost Accounting (MFCA), Social Network Analysis (SNA), and Life Cycle Assessment (LCA) - are used in order to place the indicator system on a solid and robust foundation and to adequately meet the multi-faceted sustainability perspectives in the form of a combinatorial application for deriving suitable quantitative indicators for all three (environmental, economic, social) dimensions of sustainability. The indicator system, once embedded in an Information Technology (IT)-supported IS tool, contributes crucially to the technology-enabled environment of IS systems, driving sustainability trajectories.
\end{abstract}

Keywords: industrial symbiosis; industrial ecology; indicator system; sustainability targets; resource efficiency; resource productivity; sustainability performance measurement

\section{Introduction}

Industrial Symbiosis (IS) is a systematic and collective (business) approach to optimizing the use of materials and energy among cross-sectoral industries (Chertow 2004; Herczeg et al. 2016) in order to initiate and exhaust extended cascading systems; it is associated with (synergistic) environmental, technical, social, and economic benefits (Ehrenfeld and Gertler 1997; Chertow 2004; van Berkel et al. 2009; Sokka et al. 2010; Herczeg et al. 2016; Chertow et al. 2019; Domenech et al. 2019). "Industrial symbiosis, as part of the emerging field of industrial ecology, demands resolute attention to the flow of materials and energy through local and regional economies. (... ) Industrial symbiosis engages traditionally separated industries in a collective approach to competitive advantage involving physical exchange of materials, energy, water, and/or by-products. The keys to industrial symbiosis are collaboration and synergistic possibilities offered by geographic proximity." (Chertow 2000, pp. 313-14). Li (2018) defines IS as the exploration of "ways to establish knowledge webs of novel 
material, energy, and waste exchanges and business core processes to facilitate the development of networks of synergies within and across different companies to support the development of high levels of nearly closed-loop material exchanges and efficiency of energy cascading within and across industrial ecosystems." (Li 2018, p. 35). This implies cross-sectoral collaboration within industrial communities by connecting the supply and demand of various companies (van Berkel et al. 2009; van Capelleveen et al. 2018; Domenech et al. 2019) through the exchange of material, energy, water, and human resources (Herczeg et al. 2016; Ruiz-Puente and Bayona 2017; Chertow et al. 2019).

This can be achieved through controlled resource and information flows at the inter-company level, facilitated by cross-organizational Information Technology (IT)-supported IS tools. The progress and development of IS software tools offer various opportunities for many applications in IS systems, especially for the identification of IS activities and synergistic connections, resource and information flow management, relationship management of the IS actors, and community building, amongst others. For monitoring and controlling the development and progress of an IS system, an indicator system must be set up to standardize and assess the IS (sustainability) performance. As Liu et al. (2018) stated, there is no agreed indicator system for an IS system. Therefore, this study aims to present a quantitative indicator system to enable the tracking of set sustainability targets of an IS system in Industrial Parks (IPs) for goal-directed IS management. The presented guiding framework encourages IP members in IS systems to set sustainability objectives and to evaluate and track their performance over time with a quantitative indicator system. The indicator system, once embedded in an IT-supported IS tool, contributes crucially to the technology-enabled environment of IS systems, driving sustainability trajectories.

\section{Results}

\subsection{Industrial Symbiosis Case Studies}

Figure 1 shows the schematic overview of a company's production process with the corresponding input and output resource flows, which already indicate the points of contact for IS activities, leading to economic, environmental, and social benefits. It was derived from the analyzed IS case studies to extract and abstract the points of contact for IS possibilities.

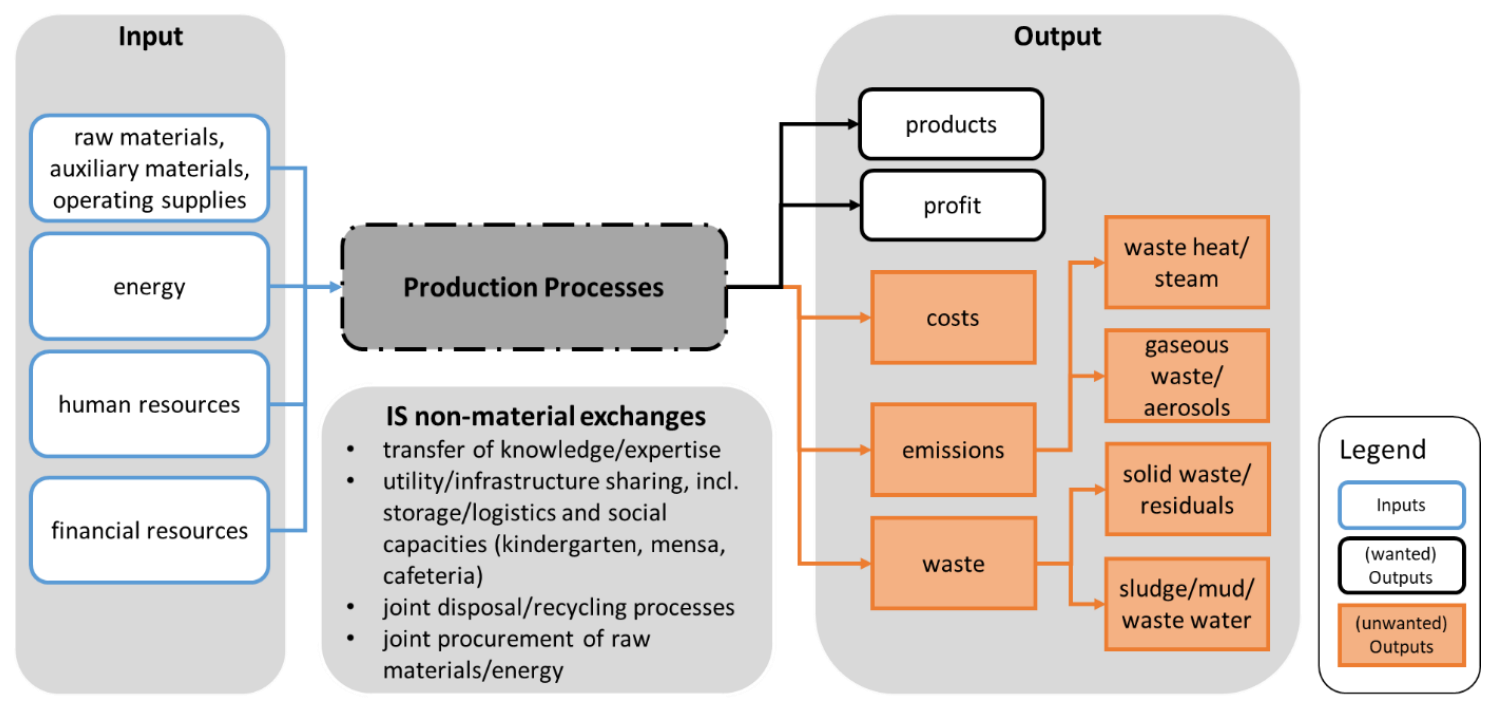

Figure 1. Schematic overview of a company's points of contact for Industrial Symbiosis (IS) activities.

In this IS context, many companies re-evaluate their "waste" streams as new business opportunities or extended business models. For example, waste heat/excessive steam can be forwarded to other companies (Mirata 2004; Pakarinen et al. 2010; Yu et al. 2015; Earley 2015). 
A smeltery in China recovered raw materials out of gaseous waste/aerosol, sludge/mud, and solid waste by filtering, extracting, concentrating, and compressing the resources out of each waste stream (Yuan and Shi 2009). The Guitang Group in China approached a disposal problem by using their sludge as the calcium carbonate feedstock for a new cement plant while reducing residual and waste flows (Zhu et al. 2008).

Gaseous/aerosol waste streams such as fly ash can be further processed as cement additives (Dong et al. 2013; Golev et al. 2014; Cui et al. 2018) or soil additives (Notarnicola et al. 2016; Bain et al. 2010).

Wastewater from food processing companies (such as olives, cereals, fruit, and vegetables) can be further utilized as fertilizer (Chertow 2008; Notarnicola et al. 2016) or for the irrigation of agricultural land; the respective organic residual (solid) waste can be re-processed to animal/fish feeding (material utilization) (Chertow 2007; Alkaya et al. 2014) or biogas and biofuel (energetic utilization) (Alkaya et al. 2014). The digestate of a biogas plant can further serve as fertilizer (Martin 2013; Alkaya et al. 2014).

Furthermore, IS activities can lead to the buildup of IS networks not only across different supply chains, but also along the supply chain of one industry. For example, Yang and Feng (2008) investigated the Chinese IS of the Nanning Sugar Industry, which incorporated affiliated companies centered around their core business of sugar production to (re-)process the residual and waste flows of the mother company (Yang and Feng 2008). Enterprises of cane farming, paper, alcohol, health products, and the cement industry were all located at the upstream or the downstream of the main sugar production, extending their own core business to an entire IS supply chain (Yang and Feng 2008). These IS activities led to various environmental, social, and economic benefits; for example, reduced costs, pollution controlling fees and environmental impacts, new jobs, and innovation for advanced business models were created, and the supply of raw materials and material quality were ensured (Yang and Feng 2008). Additionally, a sugar company in the Ulsan Industrial Park in South Korea had similar experiences by expanding the company's own collection of downstream companies, generating new revenues (Park et al. 2008). With the utilization of almost all residual and waste flows of sugar production, a better product quality was achieved, as well as reduced environmental emissions and disposal costs (Park et al. 2008).

\subsection{Applied Methods in Industrial Symbiosis Systems}

IS systems can be investigated by various quantitative methods (Kastner et al. 2015). Table 1 presents an overview of the methods applied in the context of IS systems. Certainly, there are other methods that can be used in the IS context (Kastner et al. 2015); the ones listed here refer exclusively to the results of the conducted case study analysis, which revealed three core methods that have been applied most: Material Flow Analysis (MFA), Life Cycle Assessment (LCA), and Social Network Analysis (SNA). These findings are very close to congruent to the results of other researchers (Kastner et al. 2015; Felicio et al. 2016; Li et al. 2017; Huang et al. 2019), who ascertained that the most widely used methods for IS systems are MFA (Geng et al. 2012; Sendra et al. 2007; Yong et al. 2009), LCA (Sokka et al. 2010; Sokka et al. 2011), and environmental indicators (Kurup and Stehlik 2009; Pakarinen et al. 2010; Zhu et al. 2010).

According to the three dimensions (ecological, economic, social) of sustainability, the results of the case study analysis revealed that most of the applied methods cover the environmental aspects (SFA, MFA, emergy analysis, exergy analysis, eLCA); only one method addresses both the economic (MFCA) and social aspects (SNA). Furthermore, it shows that the environmental LCA (eLCA) was predominantly applied in the context of IS systems. 
Table 1. Overview of methods applied in the context of IS systems.

\begin{tabular}{|c|c|c|}
\hline Method & Description & References \\
\hline $\begin{array}{l}\text { Social Network Analysis } \\
\text { (SNA) }\end{array}$ & $\begin{array}{l}\text { Investigates social structures of networks and } \\
\text { characterizes elements within the network in } \\
\text { terms of nodes (e.g., individual actors, } \\
\text { companies, people) and the connecting ties or } \\
\text { links (relationships or interactions). }\end{array}$ & $\begin{array}{l}\text { (Ashton 2008; Doménech and Davies } \\
\text { 2009; Doménech and Davies 2011; } \\
\text { Zhang et al. 2013; Chopra and Khanna } \\
\text { 2014; Song et al. 2018) }\end{array}$ \\
\hline $\begin{array}{l}\text { Substance Flow Analysis } \\
\text { (SFA) }\end{array}$ & $\begin{array}{l}\text { Quantifies and traces the flows and stocks of one } \\
\text { specific substance/chemical or a group of } \\
\text { substances within the system under } \\
\text { consideration. }\end{array}$ & (Zhang et al. 2013; Wen and Meng 2015) \\
\hline $\begin{array}{l}\text { Material Flow Analysis } \\
\text { (MFA) }\end{array}$ & $\begin{array}{l}\text { Quantifies the flows and stocks of materials and } \\
\text { energy of the system under consideration in } \\
\text { physical units (e.g., } \mathrm{kg} \text { ), distinguishing between } \\
\text { input and output streams of the respective } \\
\text { processes. }\end{array}$ & $\begin{array}{l}\text { (Chertow 2008; Park et al. 2008; Yang } \\
\text { and Feng 2008; Zhu et al. 2008; van } \\
\text { Berkel et al. 2009; Yuan and Shi 2009; } \\
\text { Bain et al. 2010; Ulhasanah and Goto } \\
\text { 2012; Sun et al. 2016; Li et al. 2017; } \\
\text { Taddeo et al. 2017; Mauthoor 2017; } \\
\text { Morales et al. 2019) }\end{array}$ \\
\hline $\begin{array}{l}\text { Material Flow Cost } \\
\text { Accounting (MFCA) }\end{array}$ & $\begin{array}{l}\text { Traces and quantifies the flows and stocks of } \\
\text { materials and energy of the system under } \\
\text { consideration in physical and monetary units; } \\
\text { especially the material losses, non-/by-product, } \\
\text { and waste flows are evaluated. }\end{array}$ & $\begin{array}{l}\text { (Viere et al. 2011; Ulhasanah and Goto } \\
\text { 2012; Lütje et al. 2018; Lütje et al. 2019a) }\end{array}$ \\
\hline $\begin{array}{l}\text { Life Cycle Assessment } \\
\text { (LCA) }\end{array}$ & $\begin{array}{l}\text { Quantifies the flows and stocks of materials and } \\
\text { energy of the system under consideration and } \\
\text { assesses the associated environmental impacts, } \\
\text { such as global warming and eutrophication } \\
\text { potential. }\end{array}$ & $\begin{array}{l}\text { (Sokka et al. 2010; Ulhasanah and Goto } \\
\text { 2012; Marinos-Kouris and Mourtsiadis } \\
\text { 2013; Sacchi and Ramsheva 2017; } \\
\text { Marconi et al. 2018; Martin and Harris } \\
\text { 2018; Chertow et al. 2019) }\end{array}$ \\
\hline Emergy analysis & $\begin{array}{l}\text { Emergy is an expression of all the energy } \\
\text { consumed in direct and indirect transformations } \\
\text { in the processes to generate a product or service; } \\
\text { therefore, emergy analysis converts the } \\
\text { thermodynamic basis of all forms of energy, } \\
\text { resources, and human services into equivalents of } \\
\text { a single form of energy (usually solar emjoules). }\end{array}$ & $\begin{array}{l}\text { (Geng et al. 2014; Sun et al. 2016; } \\
\text { Liu et al. 2018) }\end{array}$ \\
\hline Exergy Analysis & $\begin{array}{l}\text { Is a thermodynamic analysis technique, assessing } \\
\text { the thermodynamic performance of processes } \\
\text { and systems, identifying the causes and locations } \\
\text { of thermodynamic losses. }\end{array}$ & (Seager and Theis 2002) \\
\hline
\end{tabular}

\subsection{Quantitative Indicator System}

Figure 2 shows the guiding framework for the sustainability performance of an IS system; its content and approach design is oriented to the three types of knowledge (system, transformative, and normative knowledge), which have their roots in the fields of transdisciplinarity and sustainability sciences (Lang et al. 2012). From this (normative) sustainability perspective, the IS entities could envision a desired future state of their IS systems; this could be, for example, a "zero waste", "zero emission," or "CO2-neutral" park, or that the IP pursues to align its business performance to the science-based targets (SBT) ${ }^{1}$ (SBTi 2019). After investigating the status quo of the system under consideration, possible future scenarios could be developed with the method of scenario planning (beginning from the actual state). In accordance with the defined goals or pursued sustainability trajectory, scenarios of optimally utilized IS systems can be developed. Once the desired future vision is defined, various transformation pathways from the desired future to the actual state can be elaborated

1 Science-based targets (SBT) were established by the Science-Based Targets initiative to drive corporate climate action that is aligned to meet the goals of the Paris agreement in 2015- to limit global warming to well below $2{ }^{\circ} \mathrm{C}$ above pre-industrial levels. 
with the method of backcasting (planning possible measures/milestones backward, which then will be operated forward). This process can include all share- and stakeholders.

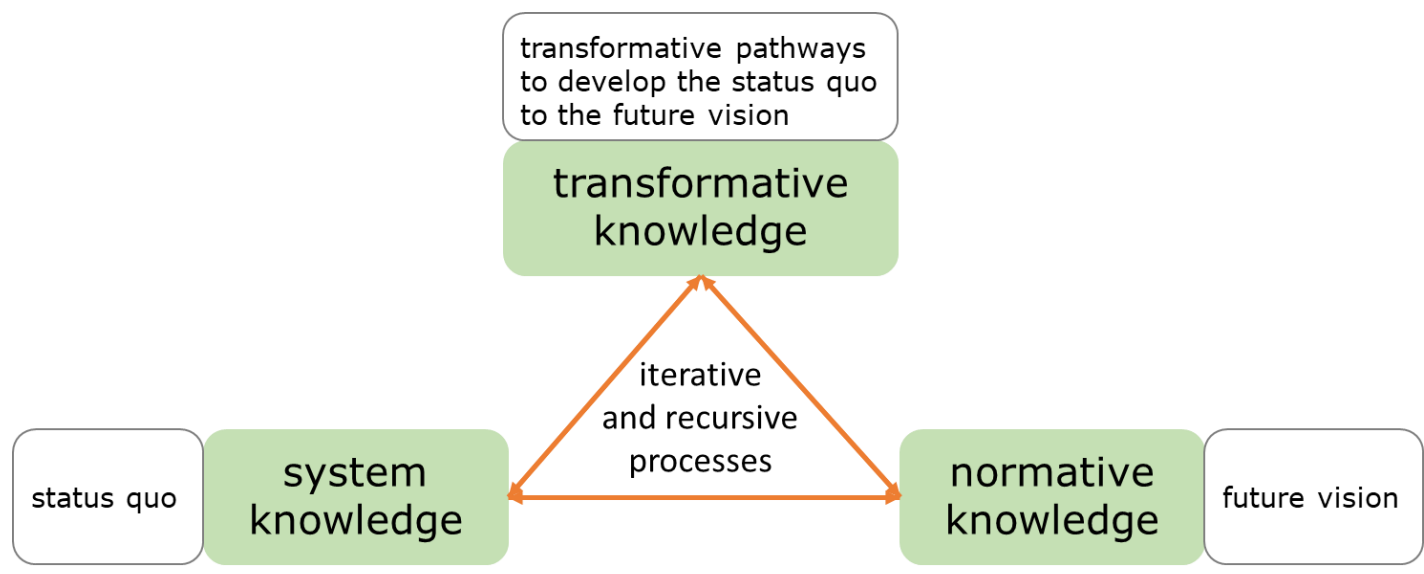

Figure 2. Guiding framework for the sustainability performance of an IS system.

By setting up a sustainability (key performance) indicator system which is in line with the quantifiable goals, the progress of the IS system can be continuously tracked and monitored. If an overarching organizational unit or a core team of the IS system is established, it could control and push the IS performance towards the trajectory of circular economy and sustainable development. Defining the (sustainability) goal of the IS system is crucial in order to arrange the approach and transformative pathways (corresponding suitable IS measures) in a targeted manner.

A general guiding systematic approach can support the development process of an indicator system:

\section{What is the overall purpose of the IS system?}

An example of an answer could be: To contribute to sustainable development and circular economy.

\section{According to which (gradual) goals and criteria should the IS system be aligned?}

This could be, for example, a target orientation towards a "zero waste", "zero emission", "CO2-neutral", or SBT park.

\section{What are requirements of the IS system?}

One possible answer could be: The essential requirements of an IS system can be summarized briefly: (1) Optimize/maximize the social and economic benefit, (2) minimize environmental burden, and (3) operate as a resilient and adaptive system. Thus, the overall sustainability contribution of an IS system can be assessed as an increase in resource productivity and efficiency, with positive social impacts and a continuously well-operating system.

\section{What should be measured?}

As already displayed in Figure 1, inputs of financial, human, and environmental (material, water, energy, land use) resources are required, and simultaneously, outputs of economic, social, and environmental impacts are generated. Each category of input- and output-related resources and impacts can be measured by specific indicators. 


\section{How should these be measured?}

In such a systematic framework, input-related indicators-addressing financial, human, and environmental resource properties-and output-related indicators-addressing economic, social, and environmental impact categories — can be developed.

Once the IP sets its quantitative indicator system, a base year shall be chosen and measured so that a time series can be tracked for each indicator. Then, a balance sheet can be implemented, in which the absolute and relative change values in relation to the values of the base year of each individual indicator can be recorded. This approach enables goal-directed IS management, while the continuous improvement processes and the yearly progresses of the IS system can be traced by the indicator time series (referenced to a base year). If necessary, measures can be taken if the performance does not correspond to the desired progress. It is recommended to define an overarching target for the entire IP and a respective roadmap with quantifiable targets and milestones to ensure a goal-oriented IS management.

On the basis of the systematics developed, the indicators were derived and further developed in line for the IS performance measurement. The following general, environmental, economic, and social indicator sets do not claim to be exhaustive, but should be successively extended and derived from common methods and standards to facilitate a systematic approach and data collection/analysis. They represent example systems that can be adapted according to the specific target orientation of each IS system, which is defined by the IP itself, since the objectives and priorities are set by the respective members of the industrial estate.

An IS general indicator system was developed for the aspects of IS structure, IS activity, IS knowledge transfer, IS system resilience, and adaptability (Table 3). It can be set up in order to generate an overview of the current state and activity level of the IS system and to get a glimpse of where the journey can go in terms of IS (sustainability) performance. The special indicators are resilience and system adaptability. Valenzuela-Venegas Guillermo et al. (2018) developed a resilience indicator which is based on two sub-indicators: The network connectivity index and flow adaptability index. The network connectivity index considers the number of connections among the entities while evaluating the minimum and maximum number of connections, in order to measure the endurance of the entire network system against possible disruptive events (e.g., loss of an entity) (Valenzuela-Venegas Guillermo et al. 2018). The flow adaptability index quantifies the necessary (material) flows and the capacities of the entities to compensate a disruption in the system (e.g., fluctuating material flows) (Valenzuela-Venegas Guillermo et al. 2018).

Table 2. IS general indicator system.

\begin{tabular}{|c|c|c|}
\hline Indicator & \multirow{2}{*}{ Unit } & \multirow{2}{*}{ References } \\
\hline IS Structure & & \\
\hline $\begin{array}{l}\text { number of overarching/special IS organizational units } \\
\text { number of participating entities in the IS system } \\
\text { density of IS system } \\
\text { number of joint disposal companies } \\
\text { number of joint supplier companies } \\
\text { number of joint logistics companies }\end{array}$ & $\begin{array}{l}\# \\
\# \\
\# \text { \#IS entities } \\
\# \text { entities in entire IP } \\
\# \\
\# \\
\#\end{array}$ & $\begin{array}{c}\text { (UNIDO 2019; } \\
\text { own suggestions) }\end{array}$ \\
\hline \multicolumn{3}{|l|}{ IS Activity } \\
\hline $\begin{array}{l}\text { number of IS connections } \\
\text { degree of interconnectivity } \\
\text { number of exchanged resources } \\
\text { degree of resource exchange activity } \\
\text { number of water networks } \\
\text { activity degree of water network } \\
\text { number of material networks } \\
\text { activity degree of material network } \\
\text { number of energy networks }\end{array}$ & $\begin{array}{l}\# \\
\frac{\# \text { IS connections }}{\# \text { IS entities }} \\
\# \\
\frac{\# \text { exchanged resources }}{\# \text { IS entities }} \\
\# \\
\frac{m^{3} I S \text { water network }}{m^{3} I P \text { water consumption }} \\
\# \\
\frac{k g \text { IS material network }}{\mathrm{kg} I P \text { material consumption }} \\
\#\end{array}$ & $\begin{array}{c}\text { (UNIDO 2019; } \\
\text { own suggestions) }\end{array}$ \\
\hline
\end{tabular}


Table 3. IS general indicator system.

\begin{tabular}{|c|c|c|}
\hline Indicator & \multirow{2}{*}{ Unit } & \multirow{2}{*}{ References } \\
\hline IS Activity & & \\
\hline activity degree of energy network & $\frac{\text { MWh IS energy network }}{\text { MWh IP energy consumption }}$ & \\
\hline number of knowledge networks & \# & \\
\hline number of IS meetings addressing IS measures & \# & \\
\hline number of identified IS opportunities & \# & \\
\hline number of planned IS activities & \# & \\
\hline number of IS activities that are being implemented & \# & \\
\hline number of implemented IS activities & \# & \\
\hline number of IS consultations & \# & \\
\hline number of IS system analyses & $\#$ & \\
\hline investments in IS consultations & $\$$ & \\
\hline investments in IS system analyses & $\$$ & \\
\hline investments in IS measures & $\$$ & \\
\hline received (public) funding to expand IS system & $\$$ & \\
\hline \multicolumn{3}{|l|}{ IS Knowledge Transfer } \\
\hline number of education/training events addressing IS & $\#$ & (UNIDO 2019; \\
\hline number of educated/trained persons concerning IS & $\#$ & own suggestions) \\
\hline \multicolumn{3}{|l|}{ IS System Resilience and Adaptability } \\
\hline network connectivity indexflows adaptability index & & $\begin{array}{l}\text { (Valenzuela-Venegas } \\
\text { Guillermo et al. 2018) }\end{array}$ \\
\hline
\end{tabular}

Table 4 shows an IS environmental indicator system, specialized to the performance of IS cascading loops/systems (resources, emissions, etc. saved through IS activities). It differentiates input- and output-related indicators. While most of the presented indicators are easier to understand, the following two require further explanation:

Table 4. IS environmental indicator system.

\begin{tabular}{|c|c|c|}
\hline Indicator & \multirow{2}{*}{ Unit } & \multirow{2}{*}{ References } \\
\hline Input-Related Indicators & & \\
\hline $\begin{array}{l}\text { saved primary material resources } \\
\text { saved primary water resources } \\
\text { saved primary energy resources } \\
\text { saved land use } \\
\text { recycled solid waste } \\
\text { recycled liquid waste/water } \\
\text { recycled/used gaseous/aerosol waste } \\
\text { material recovery rate } \\
\text { recycled water rate } \\
\text { renewable energy produced in the IS system }\end{array}$ & $\begin{array}{l}\mathrm{kg} \\
\mathrm{m}^{3} \\
\mathrm{MWh}^{2} \\
\mathrm{~m}^{2} \\
\mathrm{~kg} \\
\mathrm{~m}^{3} \\
\mathrm{~m}^{3} \\
\% \\
\% \\
\mathrm{MWh}\end{array}$ & $\begin{array}{l}\text { (Krajnc and Glavič 2003; Trokanas et al. 2014; } \\
\text { Valenzuela-Venegas Guillermo et al. 2018; Chertow 2008; Park et } \\
\text { al. 2008; Yang and Feng 2008; Zhu et al. 2008; } \\
\text { van Berkel et al. 2009; Yuan and Shi 2009; Bain et al. 2010; } \\
\text { Ulhasanah and Goto 2012; Sun et al. 2016; Li et al. 2017; Taddeo } \\
\text { et al. 2017; Mauthoor 2017; Morales et al. 2019; Sokka et al. 2010; } \\
\text { Marinos-Kouris and Mourtsiadis 2013; Geng et al. 2014; } \\
\text { Sacchi and Ramsheva 2017; Marconi et al. 2018; Martin and } \\
\text { Harris 2018; } \\
\text { Chertow et al. 2019; UNIDO 2019) }\end{array}$ \\
\hline \multicolumn{3}{|l|}{ Output-Related Indicators } \\
\hline $\begin{array}{l}\text { reduced } \mathrm{CO} 2 \text { emissions } \\
\text { reduced } \mathrm{NOx} \text { emissions } \\
\text { reduced } \mathrm{SO} 2 \text { emissions }\end{array}$ & $\begin{array}{l}\mathrm{kg} \mathrm{CO} 2 \mathrm{e} \\
\mathrm{kg} \mathrm{NOx} \\
\mathrm{kg} \mathrm{SO} 2\end{array}$ & $\begin{array}{l}\text { (Sokka et al. 2010; Ulhasanah and Goto 2012; } \\
\text { Marinos-Kouris and Mourtsiadis 2013; Geng et al. 2014; Sacchi } \\
\text { and Ramsheva 2017; Marconi et al. 2018; Martin and Harris 2018; } \\
\text { Chertow et al. 2019; UNIDO 2019) }\end{array}$ \\
\hline change in chemical exergy & $\mathrm{J} / \mathrm{mol}$ & $\begin{array}{l}\text { (Seager and Theis 2002; Valenzuela-Venegas Guillermo et al. } \\
\text { 2018) }\end{array}$ \\
\hline Relative Emergy Savings (RES) & solar emjoules & $\begin{array}{l}\text { (Geng et al. 2014; Sun et al. 2016; Valenzuela-Venegas Guillermo } \\
\text { et al. 2018; } \\
\text { Liu et al. 2018) }\end{array}$ \\
\hline
\end{tabular}

Generally, energy consists of two parts: Exergy and anergy. Exergy is the part of the total energy of a system that is actually usable and can do work, anergy is the total opposite. The general relationship between exergy and the material life cycle involves high-exergy resources (low entropy) being extracted from the environment, processed and consumed by the economy, and returned to the environment as low-exergy materials, i.e., waste (high entropy) (Seager and Theis 2002). So, over the phases of the 
entire life cycle, exergy is reduced, while the share of anergy and entropy increases; i.e., in order to keep a system at a certain level, new usable energy must be supplied and consumed "from outside" again and again.

Emergy is an expression of all of the past work performed by the environment, economy, and society in the entire process chain to generate a product or service (incl. all of the energy consumed in direct and indirect transformations). Due to the incorporation of all previous work and services, an emergy sustainability index is a single comprehensive, aggregated indicator, and can represent the sustainability performance of the system under consideration (Sun et al. 2016). By studying the Shenyang Economic and Technological Development Zone (SETDZ) in China, Geng et al. (2014) found out that emergy indicators are not all-encompassing measures of environmental and economic performances, but are appropriate to indicate the overall performance of one IP, especially when these are complemented with other methods and respective indicators. For example, the emergy indicator of relative emergy savings (RES) can be defined as the ratio of avoided inputs through all of the IS activities to total emergy inputs without related IS activities (Geng et al. 2014). Furthermore, this indicator can be extended to consider the entire life cycles of products and services.

Table 5 shows an IS economic indicator system. The input- and output-related indicators generally address cost savings achieved through IS activities. While most of the presented indicators are simple to understand, the following two require further explanation:

Table 5. IS economic indicator system.

\begin{tabular}{|c|c|c|}
\hline Indicator & \multirow{2}{*}{ Unit } & \multirow{2}{*}{ References } \\
\hline Input-Related Indicators & & \\
\hline cost savings for human resources & $\$$ & \multirow{6}{*}{$\begin{array}{l}\text { (Ulhasanah and Goto 2012; } \\
\text { Lütje et al. 2018; Lütje et al. } \\
\text { 2019a; UNIDO 2019) }\end{array}$} \\
\hline cost savings for material & $\$$ & \\
\hline cost savings for water & $\$$ & \\
\hline cost savings for energy & $\$$ & \\
\hline cost savings for land use & $\$$ & \\
\hline production-cost-specific IS cost savings & $\frac{I S \text { cost savings }(\$)}{\text { production costs }(\$)}$ & \\
\hline Emdollar value of Total Emergy Savings (ETS) & $\$$ & $\begin{array}{l}\text { (Geng et al. 2014; } \\
\text { Sun et al. 2016; Liu et al. 2018) }\end{array}$ \\
\hline \multicolumn{3}{|l|}{ Output-Related Indicators } \\
\hline cost savings for disposal/recycling & $\$$ & \multirow{5}{*}{$\begin{array}{c}\text { (Trokanas et al. 2014; own } \\
\text { suggestions) }\end{array}$} \\
\hline cost savings for $\mathrm{CO} 2$ taxes & $\$$ & \\
\hline cost savings for $(\mathrm{CO} 2)$ emission trading certificates & $\$$ & \\
\hline created added value & $\$$ & \\
\hline created yield & $\$$ & \\
\hline specific resource productivity & $\frac{\text { yield }(\$)}{\text { unit resource }}$ & (Wen and Meng 2015) \\
\hline yield-specific IS cost savings & $\underline{\text { IS cost savings (\$) }}$ & \multirow{2}{*}{ own suggestions } \\
\hline specific area-related IS value-added ratio & $\frac{\text { IS value-added }(\$)}{\text { area used }\left(m^{2}\right)}$ & \\
\hline
\end{tabular}

A resource productivity indicator $(\mathrm{RP})$ can reflect the interlinked relation between economic growth and specific material consumption, indicating the circular economy performance of an IS system (Wen and Meng 2015).

The Emdollar value of total emergy savings (ETS) represents the economic benefits gained by IS activities (Geng et al. 2014).

Table 6 shows an IS social indicator system. These indicators mainly address non-material IS exchanges, whereof the employees of the IP can benefit socially by establishing joint utility and infrastructure projects of kindergarten, mensa, canteen, cafeteria, or cross-company organized mobility. 
Table 6. IS social indicator system.

\begin{tabular}{|c|c|c|}
\hline Indicator & \multirow{2}{*}{ Unit } & \multirow{2}{*}{ References } \\
\hline Input-Related Indicators & & \\
\hline created number of jobs & \# & $\begin{array}{l}\text { (UNIDO 2019; } \\
\text { Geng et al. 2012) }\end{array}$ \\
\hline number of joint organized social/charity events within the IS system & \# & \\
\hline investments in joint/cross-company organized social activities & $\$$ & own suggestions \\
\hline number of utility-sharing and joint infrastructure projects & \# & \\
\hline \multicolumn{3}{|l|}{ Output-Related indicators } \\
\hline $\begin{array}{l}\text { through shared IS utilities and human resources: } \\
\text { improved environmental, health, and safety (EHS) aspects (e.g., } \\
\text { number of trainings, audits, workshops, activities) } \\
\text { improved working conditions (e.g., number of joint bargaining }\end{array}$ & \# & $\begin{array}{l}\text { (Azapagic and Perdan 2000; } \\
\text { UNIDO 2019; } \\
\text { own suggestions) }\end{array}$ \\
\hline $\begin{array}{l}\text { activities, number of joint organizations for kindergarten, canteen, } \\
\text { cafeteria, mobility) }\end{array}$ & \# & \\
\hline
\end{tabular}

\section{Discussion and Future Research}

One of the crucial first steps of this approach is the necessity of defining sustainability objectives to which the IP members in the IS system commit, as well as the system analysis of the status quo, in order to develop a roadmap with respective measures. By setting up a sustainability indicator system which is in line with the quantifiable goals, the progress of the IS system can be continuously tracked and monitored. If an overarching organizational unit or a core team of the IS system is established, it could control and push the IS performance towards the trajectory of circular economy and sustainable development. Once the corresponding sustainability contribution of IS can be evaluated in a quantifiable manner, it can thus significantly influence the further course of IS implementation and can promote the full exhaustion of IS potentials.

This work presented a holistic indicator system covering all three dimensions of sustainability. While various methods and indicators have been developed for the economic and environmental dimensions, the highest development potential and challenge lie in the setup of a social indicator system, as the social dimension is tricky to quantify. In order to build a holistic indicator system, all of the strengths and weaknesses of chosen methods and indicators must be taken into account; an indicator is just a small puzzle piece of an image of reality, which is embedded in the context of a holistic system, and is thus a number to be interpreted with caution and in relation to the overall setting.

Nevertheless, in addition to advanced technology solutions, a systematic structuring in the form of quantitative indicator systems for measuring the sustainability performance of IS systems can make a further contribution to the technology-enabled environment of IS systems. After defining the sustainability goals of the IS system, appropriate measures can be prioritized and implemented, which in turn can be tracked and monitored with an indicator system. The challenge is to formulate a common sustainability goal for the IS system and to develop informative indicators accordingly. The meaningfulness and information content of individual indicators should also be assessed carefully; for a holistic view, a large number of different indicators from the three sustainability dimensions should always be included in order to avoid a view that is too one-sided. In addition, the relations of cost-benefit and cost-value must be proportionately added; processes like data collection and evaluation also consume financial and human resources. That is why this developed indicator system is to be embedded in an IT-supported IS tool, which facilitates continuous system analysis and tracking of the IP's performance with quantitative indicators in a manageable manner for the participating companies (Lütje et al. 2019a).

Through the ongoing corporate digitalization (including data collection and processes), companies can track their economic, social, and ecological performance through advanced and smart Information 
and Communication Technology (ICT). IPs may evolve into Smart Industrial Parks (SIP) with intelligence monitoring, information processing, and risk prevention (Li et al. 2017). Sophisticated Environmental Management Information Systems (EMIS) need to be established within IPs to provide a reliable data and analysis basis for more valuable information and substantiated decision making which considers all three sustainability pillars and their respective (potential) trade-offs among them. It is therefore all the more important to establish a (standardized) indicator system in order to track progress towards sustainable trajectories and/or the defined objectives of the IS entities. Such an indicator system needs to be compatible with the goals defined by the IS entities, which can be, for example, a zero-waste, zero-emission, CO2-neutral park. This will be embedded in an overarching IT-supported IS tool (which has been already prototyped), enabling the presentation of updated or real-time indicators from entered data of the participating entities and the provision of the current status of the IS system. Future research will address a virtual simulation of an IS system, pursuing a sustainability target (e.g., converging to a zero-waste park), which will be tracked by a compatible set of indicators applying an IT-supported IS tool. From a visionary perspective, a standardized quantitative indicator system could allow benchmarking possibilities in the future and IS performance comparisons on a regional or (multi-)national scale, up to an international scale.

In the context of IS systems, the application of concepts such as Industry 4.0, Artificial Intelligence (AI) (Lütje et al. 2019b), Smart Industrial Parks (SIP), etc. can provide promising solution approaches in order to remarkably advance the research area and scope of action of IS, and hence significantly drive the dynamics and speed of (further) development of IS systems.

\section{Materials and Methods}

This study is embedded in an overarching work project, addressing the development of an IT-supported Industrial Symbiosis (IS) tool for the identification of IS opportunities and management of IS in Industrial Parks (IPs). The development of an IS web tool was designed based on previous research activities (Figure 3). Requirements Engineering (RE), also called requirements analysis, is one of the main activities of the software or system development process, which defines the requirements for the system to be developed with the help of a systematic procedure from the project idea of the goals to a complete set of requirements. This was underpinned by extensive systematic literature research and analysis of existing case studies, as well as interviews with IS experts and practitioners. Based on that, a first prototype was developed, deploying methods such as Material Flow Analysis (MFA), Material Flow Cost Accounting (MFCA), Social Network Analysis (SNA), and Life Cycle Assessment (LCA, optionally) in a combinatorial approach for the IS context. These methods were identified to be the most applied and well-established approaches in IS systems (Lütje et al. 2019a; Huang et al. 2019; Li et al. 2017; Kastner et al. 2015).

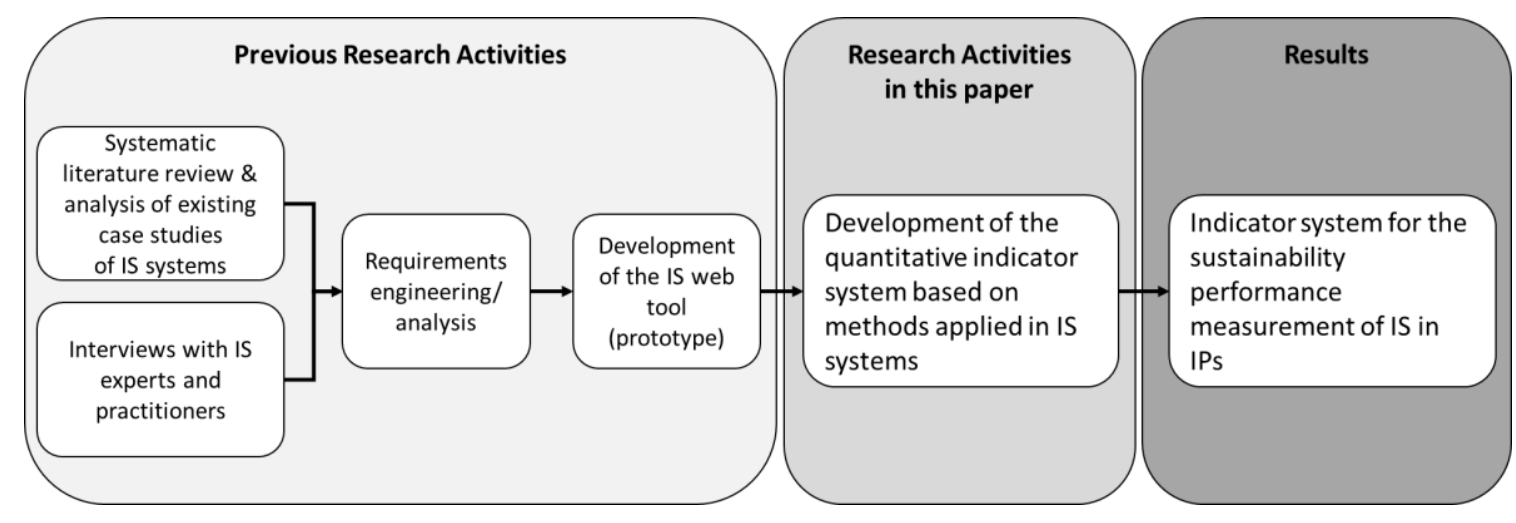

Figure 3. Design of the research approach. 
A comprehensive systematic literature review, deploying forward and backward snowballing techniques, was carried out to analyze a total of 70 freely accessible papers, including 55 case studies, to extract knowledge of IS for the following research question (RQ): How can the sustainability performance of an IS system (especially industrial parks) be measured and tracked?

Publications were sourced from the following databases, such as Thomson Reuters Web of Knowledge, ResearchGate, google scholar, Scopus, CORE, and Directory of Open Access Journals. The queries searched for the following terms: "Industrial symbiosis", "industrial symbiosis indicator", and "(smart/eco) industrial park". The selection of scientific papers was aligned to three aspects, so once a paper addressed the topics of: 1) The application of a method in an IS context, 2) IS case studies, 3) (social, environmental, economic) indicators in an IS context, they were chosen for this study. Only publications in English and German were included in the study.

This paper deals with the development of an indicator system to measure and track the IS sustainability performance in IPs towards set sustainability targets over time. This is then integrated into the IS web tool in order to be able to automatically present updated or real-time indicators from the entered data. The presented indicators were derived from the implemented methods and analyzed literature. The indicators were aligned to the following system matrix, which covers the three dimensions (environmental, social, economic) of sustainability (Table 7).

Table 7. Design of the indicator matrix.

\begin{tabular}{cccc}
\hline & $\begin{array}{c}\text { Environmental } \\
\text { Dimension }\end{array}$ & $\begin{array}{c}\text { Economic } \\
\text { Dimension }\end{array}$ & $\begin{array}{c}\text { Social } \\
\text { Dimension }\end{array}$ \\
\hline $\begin{array}{c}\text { Input-Related } \\
\text { Indicators }\end{array}$ & $\begin{array}{c}\text { e.g., through IS saved } \\
\text { primary resources }\end{array}$ & $\begin{array}{c}\text { e.g., through IS saved primary } \\
\text { material costs }\end{array}$ & $\begin{array}{c}\text { e.g., through IS } \\
\text { created jobs }\end{array}$ \\
\hline $\begin{array}{c}\text { Output-Related } \\
\text { Indicators }\end{array}$ & $\begin{array}{c}\text { e.g., through IS } \\
\text { reduced emissions }\end{array}$ & $\begin{array}{c}\text { e.g., through IS saved } \\
\text { disposal costs }\end{array}$ & $\begin{array}{c}\text { e.g., through IS improved } \\
\text { working conditions }\end{array}$ \\
\hline
\end{tabular}

It differentiates process/production input- and output-related indicators, while referring to either environmental, social, or economic resources and impacts. Furthermore, a general indicator system was deduced, differentiating indicators for the following aspects: IS structure, IS activity, IS knowledge transfer, IS system resilience, and adaptability.

On the one hand, this structuring of the system matrix shall ensure a systematic indicator set balancing all three dimensions of sustainability in order to meet the multi-faceted perspectives of sustainable development. On the other hand, differentiated input- and output-related indicators highlight "localized" points of contact, as well as leverage or intervention points, to guide appropriate measures for improving the sustainability performance of IS systems. Quantifiable sustainability goals and their respective indicators, once incorporated into an IT-supported IS tool, enable the systematic tracking of set sustainability targets in the technology-enabled environment of IS systems, guiding sustainability trajectories.

Author Contributions: Conceptualization, A.L. and V.W.; methodology, A.L.; validation, A.L. and V.W.; formal analysis, A.L.; investigation, A.L.; resources, A.L.; data curation, V.W.; writing-original draft preparation, A.L.; writing-review and editing, V.W.; visualization, A.L.; supervision, V.W.; project administration, V.W.; funding acquisition, V.W. All authors have read and agreed to the published version of the manuscript.

Funding: This doctoral research work is co-financed by funds from the Berlin Equal Opportunities Programme.

Conflicts of Interest: The authors declare no conflict of interest.

\section{References}

Alkaya, Emrah, Merve Böğürcü, and Ferda Ulutaş. 2014. Industrial Symbiosis in Iskenderun Bay: A journey from Pilot Applications to a National Program in Turkey. Paper presented at the SYMBIOSIS 2014, Athens, Greece, June 19-21. 
Ashton, Weslynne Stacey. 2008. Understanding the organization of industrial ecosystems: A social network approach. Journal of Industrial Ecology 12: 34-51. [CrossRef]

Azapagic, Adisa, and Slobodan Perdan. 2000. Indicators of sustainable development for industry: A General Framework. Process Safety and Environmental Protection 78: 243-61. [CrossRef]

Bain, Ariana, Megha Shenoy, Weslynne Stacey Ashton, and Marian Ruth Chertow. 2010. Industrial symbiosis and waste recovery in an Indian industrial area. Resources, Conservation and Recycling 54: 1278-87. [CrossRef]

Chertow, Marian Ruth. 2000. Industrial symbiosis: Literature and taxonomy. Annual Reviews Energy Environment 25: 313-37. [CrossRef]

Chertow, Marian Ruth. 2004. Industrial Symbiosis. Encyclopedia of Energy 3: 407-15.

Chertow, Marian Ruth. 2007. Uncovering industrial symbiosis. Journal of Industrial Ecology 11: 11-30. [CrossRef]

Chertow, Marian Ruth. 2008. Industrial Ecology in a Developing Context. In Sustainable Development and Environmental Management. Edited by Corrado Clini and Maria Lodovica Gullino. Dordrecht: Springer, pp. 1-19.

Chertow, Marian Ruth, Matthew Gordon, Peter Hirsch, and Anu Ramaswami. 2019. Industrial symbiosis potential and urban infrastructure capacity in Mysuru, India. Environmental Research Letters. in press. [CrossRef]

Chopra, Shauhrat, and Vikas Khanna. 2014. Understanding resilience in industrial symbiosis networks: Insights from network analysis. Journal of Environmental Management 141: 86-94. [CrossRef]

Cui, Hua, Changhao Liu, Raymond Côté, and Weifeng Liu. 2018. Understanding the Evolution of Industrial Symbiosis with a System Dynamics Model: A Case Study of Hai Hua Industrial Symbiosis, China. Sustainability 10: 3873. [CrossRef]

Doménech, Teresa, and Michael Davies. 2009. The social aspects of industrial symbiosis: The application of social network analysis to industrial symbiosis networks. Progress in Industrial Ecology 6: 68-99. [CrossRef]

Doménech, Teresa, and Michael Davies. 2011. Structure and morphology of industrial symbiosis networks: The case of Kalundborg. Procedia Social Behavior Science 10: 79-89. [CrossRef]

Domenech, Teresa, Raimund Bleischwitz, Asel Doranova, Dimitris Panayotopoulos, and Laura Roman. 2019. Mapping Industrial Symbiosis Development in Europe-Typologies of networks, characteristics, performance and contribution to the Circular Economy. Resources, Conservation E Recycling 141: 76-98. [CrossRef]

Dong, Liang, Tsuyoshi Fujita, Hui Zhang, Ming Dai, Minoru Fujii, Satoshi Ohnishi, Yong Geng, and Zhu Liu. 2013. Promoting low-carbon city through industrial symbiosis: A case in China by applying HPIMO model. Energy Policy 61: 864-73. [CrossRef]

Earley, Katharine. 2015. Industrial symbiosis: Harnessing waste energy and materials for mutual benefit. Renewable Energy Focus 16: 75-77. [CrossRef]

Ehrenfeld, John, and Nicholas Gertler. 1997. Industrial Ecology in Practice-The Evolution of Interdependence at Kalundborg. Journal of Industrial Ecology 1: 67-79. [CrossRef]

Felicio, Miriã, Daniel Amaral, Kleber Esposto, and Xavier Gabarrell Durany. 2016. Industrial symbiosis indicators to manage eco-industrial parks as dynamic systems. Journal of Cleaner Production 118: 54-64. [CrossRef]

Geng, Yong, Jia Fu, Joseph Sarkis, and Bing Xue. 2012. Towards a national circular economy indicator system in China: An evaluation and critical analysis. Journal of Cleaner Production 23: 216-24. [CrossRef]

Geng, Yong, Zuoxi Liu, Bing Xue, Huijuan Dong, Tsuyoshi Fujita, and Anthony Chiu. 2014. Emergy-based assessment on industrial symbiosis: A case of Shenyang Economic and Technological Development Zone. Environmental Science and Pollution Research 21: 13572-87. [CrossRef]

Golev, Artem, Glen Corder, and Damien P. Giurcob. 2014. Industrial symbiosis in Gladstone: A decade of progress and future development. Journal of Cleaner Production 84: 421-29. [CrossRef]

Herczeg, Gabor, Renzo Akkerman, and Michael Zwicky Hauschild. 2016. Supply Chain Management in Industrial Symbiosis Networks. Ph.D. thesis, Technical University of Denmark, Copenhagen, Denmark, March; pp. 7-45.

Huang, Maoxing, Zhenzhen Wang, and Ting Chen. 2019. Analysis on the theory and practice of industrial symbiosis based on bibliometrics and social network analysis. Journal of Cleaner Production 213: 956-67. [CrossRef]

Kastner, Catharine A., Raymond Lau, and Markus Kraft. 2015. Quantitative Tools for Cultivating Symbiosis in Industrial Parks; A Literature Review. Cambridge: Centre for Computational Chemical Engineering, University of Cambridge. 
Krajnc, Damjan, and Peter Glavič. 2003. Indicators of Sustainable Production. Clean Technologies and Environmental Policy 5: 279-88. [CrossRef]

Kurup, Biji, and Daniela Stehlik. 2009. Towards a model to assess the sustainability implications of industrial symbiosis in eco-industrial parks. Progress in Industrial Ecology 6: 103-19. [CrossRef]

Lang, Daniel J., Arnim Wiek, Matthias Bergmann, Michael Stauffacher, Pim Martens, Peter Moll, Mark Swilling, and Christopher J. Thomas. 2012. Transdisciplinary research in sustainability science: Practice, principles, and challenges. Sustainability Science 7: 25-43. [CrossRef]

Li, Xiaohong. 2018. Industrial Ecology and Industrial Symbiosis for Environmental Sustainability-Definitions, Frameworks and Applications. London: Palgrave Pivot, ISBN 978-3-319-67500-8.

Li, Bo, Pengcheng Xiang, Mingming Hu, Chunbo Zhang, and Liang Dong. 2017. The vulnerability of industrial symbiosis: A case study of Qijiang Industrial Park, China. Journal of Cleaner Production 157: 267-77. [CrossRef]

Liu, Zhe, Michelle Adams, Raymond P. Cote, Yong Geng, Jingzheng Ren, Qinghua Chen, Weili Liu, and Xuesong Zhu. 2018. Co-benefits accounting for the implementation of eco-industrial development strategies in the scale of industrial park based on emergy analysis. Renewable and Sustainable Energy Reviews 81: 1522-29. [CrossRef]

Lütje, Anna, Andreas Möller, and Volker Wohlgemuth. 2018. A preliminary concept for an IT-supported industrial symbiosis (IS) tool using extended material flow cost accounting (MFCA)—Impulses for environmental management information systems (EMIS). In Advances and New Trends in Environmental Informatics. Edited by Hans-Joachim Bungartz, Dieter Kranzlmüller, Volker Weinberg, Jens Weismüller and Volker Wohlgemuth. Basel: Springer Nature Switzerland AG, pp. 167-81. [CrossRef]

Lütje, Anna, Martina Willenbacher, Andreas Möller, and Volker Wohlgemuth. 2019a. Enabling the identification of industrial symbiosis (IS) through information communication technology (ICT). Paper presented at the 52nd Hawaii International Conference on System Sciences (HICSS), Maui, HI, USA, January 8-11; pp. 709-19, ISBN 978-0-9981331-2-6. [CrossRef]

Lütje, Anna, Martina Willenbacher, Martin Engelmann, Christian Kunisch, and Volker Wohlgemuth. 2019b. Exploring the system dynamics of industrial symbiosis (IS) with machine learning (ML) techniques-A framework for a hybrid-approach. In Advances and New Trends in Environmental Informatics-ICT for Sustainable Solutions. Edited by Rüdiger Schaldach, Karl-Heinz Simon, Jens Weismüller and Volker Wohlgemuth. Basel: Springer Nature Switzerland AG, pp. 117-30.

Marconi, Marco, Fabio Gregori, Michele Germani, Alessandra Papetti, and Claudio Favi. 2018. An approach to favor industrial symbiosis: The case of waste electrical and electronic equipment. Procedia Manufacturing 21: 502-9. [CrossRef]

Marinos-Kouris, Dimitrios, and Andreas Mourtsiadis. 2013. Industrial symbiosis in Greece: A study of spatial allocation patterns. Fresenius Environmental Bulletin 22: 2174-81.

Martin, Michael. 2013. Industrial Symbiosis in the Biofuel Industry: Quantification of the Environmental Performance and Identification of Synergies. Ph.D. dissertation, Dissertation No. 1507. Linköping University, Linköping, Sweden, April 26.

Martin, Michael, and Steve Harris. 2018. Prospecting the sustainability implications of an emerging industrial symbiosis network. Resources, Conservation \& Recycling 138: 246-56. [CrossRef]

Mauthoor, Sumayya. 2017. Uncovering industrial symbiosis potentials in a small island developing state: The case study of Mauritius. Journal of Cleaner Production 147: 506-13. [CrossRef]

Mirata, Murat. 2004. Experiences from early stages of a national industrial symbiosis programme in the UK: Determinants and coordination challenges. Journal of Cleaner Production 12: 967-83. [CrossRef]

Morales, Manuel Eduardo, Arnaud Diemer, Gemma Cervantes, and Graciela Carrillo-González. 2019. “By-product synergy" changes in the industrial symbiosis dynamics at the Altamira-Tampico industrial corridor: 20 years of industrial ecology in Mexico. Resources, Conservation \& Recycling 140: 235-45. [CrossRef]

Notarnicola, Bruno, Giuseppe Tassielli, and Pietro Alexander Renzulli. 2016. Industrial Symbiosis in the Taranto industrial district: Current level, constraints and potential new synergies. Journal of Cleaner Production 122: 133-43. [CrossRef]

Pakarinen, Suvi, Tuomas Mattila, Matti Melanen, Ari Nissinen, and Laura Sokka. 2010. Sustainability and industrial symbiosis-The evolution of a Finnish forest industry complex. Resources, Conservation and Recycling 54: 1393-404. [CrossRef] 
Park, Hung Suck, Eldon R. Rene, Soo-Mi Choi, and Anthony S. F. Chiu. 2008. Strategies for sustainable development of industrial park in Ulsan, South Korea-From spontaneous evolution to systematic expansion of industrial symbiosis. Journal of Environmental Management 87: 1-13. [CrossRef] [PubMed]

Ruiz-Puente, Carmen, and Erik Bayona. 2017. Modelling of an industrial symbiosis network as a supply chain. Paper presented at ATHENS 2017 5th International Conference on Sustainable Solid Waste Management, Athens, Greece, June 21-24.

Sacchi, Romain, and Yana Konstantinova Ramsheva. 2017. The effect of price regulation on the performances of industrial symbiosis: A case study on district heating. International Journal of Sustainable Energy Planning and Management 14: 39-56. [CrossRef]

SBTi. 2019. Science Based Targets initiative. Available online: https://sciencebasedtargets.org/ (accessed on 23 May 2019).

Seager, Thomas P., and Thomas L. Theis. 2002. A uniform definition and quantitative basis for industrial ecology. Journal of Cleaner Production 10: 225-35. [CrossRef]

Sendra, Cristina, Xavier Gabarrell, and Teresa Vicent. 2007. Material flow analysis adapted to an industrial area. Journal of Cleaner Production 15: 1706-15. [CrossRef]

Sokka, Laura, Suvi Lehtoranta, Ari Nissinen, and Matti Melanen. 2010. Analyzing the Environmental Benefits of Industrial Symbiosis. Journal of Industrial Ecology 15: 137-55. [CrossRef]

Sokka, Laura, Suvi Pakarinen, and Matti Melanen. 2011. Industrial symbiosis contributing to more sustainable energy use-An example from the forest industry in Kymenlaakso, Finland. Journal of Cleaner Production 19: 285-93. [CrossRef]

Song, Xiaoqian, Yong Geng, Huijuan Dong, and Wei Chen. 2018. Social network analysis on industrial symbiosis: A case of Gujiao eco-industrial park. Journal of Cleaner Production 193: 414-23. [CrossRef]

Sun, Lu, Hong Li, Liang Dong, Kai Fang, Jingzheng Ren, Yong Geng, Minoru Fujii, Wei Zhang, Ning Zhang, and Zhe Liu. 2016. Eco-benefits assessment on urban industrial symbiosis based on material flow analysis and emergy evaluation approach: A case of Liuzhou City, China. Resources, Conservation \& Recycling 119: 78-88. [CrossRef]

Taddeo, Raffaella, Alberto Simboli, Anna Morgante, and Suren Erkman. 2017. The development of Industrial Symbiosis in Existing Contexts. Experiences from three Italian clusters. Ecological Economics 139: 55-67. [CrossRef]

Trokanas, Nikolaos, Franjo Cecelja, and Tara Raafat. 2014. Semantic approach for pre-assessment of environmental indicators in industrial symbiosis. Journal of Cleaner Production 96: 349-61. [CrossRef]

Ulhasanah, Nova, and Naohiro Goto. 2012. Preliminary Design of Eco-City by Using Industrial Symbiosis and Waste Co-Processing Based on MFA, LCA, and MFCA of Cement Industry in Indonesia. International Journal of Environmental Science and Development 3: 553-61. [CrossRef]

UNIDO. 2019. Eco-Industrial Parks_Achievements and key insights from the global RECP programme 2012-2018. UNIDO Report. Vienna: United Nations Industrial Development Organization, pp. 8-51.

Valenzuela-Venegas Guillermo, Henríquez-Henríquez Francisco, Marianne Boix, Ludovic Montastruc, Fernando Arenas-Araya, Jenny Miranda-Péreza, and Felipe A. Díaz-Alvarado. 2018. A resilience indicator for Eco-Industrial Parks. Journal of Cleaner Production 174: 807-20. [CrossRef]

van Berkel, Rene, Tsuyoshi Fujita, Shizuka Hashimoto, and Minoru Fujii. 2009. Quantitative Assessment of Urban and Industrial Symbiosis in Kawasaki, Japan. Environmental Science \& Technology 43: 1271-81. [CrossRef]

van Capelleveen, Guido, Chintan Amrit, and Devrim Murat Yazan. 2018. A Literature Survey of Information Systems Facilitating the Identification of Industrial Symbiosis. In From Science to Society. Progress in IS. Edited by Benôit Otjacques, Patrik Hitzelberger, Stefan Naumann and Volker Wohlgemuth. Cham: Springer International Publishing AG. [CrossRef]

Viere, Tobias, Martina Prox, Andreas Möller, and Mario Schmidt. 2011. Implications of material flow cost accounting for life cycle engineering. Paper presented at 18th CIRP International Conference on Life Cycle Engineering, Braunschweig, Germany, May 2-4.

Wen, Zongguo, and Xiaoyan Meng. 2015. Quantitative assessment of industrial symbiosis for the promotion of circular economy: A case study of the printed circuit boards industry in China's Suzhou New District. Journal of Cleaner Production 90: 211-19. [CrossRef]

Yang, Shanlin, and Nanping Feng. 2008. A case study of industrial symbiosis: Nanning Sugar Co., Ltd. in China. Resources, Conservation \& Recycling 52: 813-20. [CrossRef] 
Yong, Geng, Zhang Pan, Raymond P. Côté, and Tsuyoshi Fujita. 2009. Assessment of the National Eco-Industrial Park Standard for Promoting Industrial Symbiosis in China. Journal of Industrial Ecology 13: 15-26. [CrossRef]

Yu, Fei, Feng Han, and Zhaojie Cui. 2015. Evolution of industrial symbiosis in an eco-industrial park in China. Journal of Cleaner Production 87: 339-47. [CrossRef]

Yuan, Zengwei, and Lei Shi. 2009. Improving enterprise competitive advantage with industrial symbiosis: Case study of a smeltery in China. Journal of Cleaner Production 17: 1295-302. [CrossRef]

Zhang, Hui, Liang Dong, Huiquan Li, Tsuyoshi Fujita, Satoshi Ohnishi, and Qing Tang. 2013. Analysis of low-carbon industrial symbiosis technology for carbon mitigation in a Chinese iron/steel industrial park: A case study with carbon flow analysis. Energy Policy 61: 1400-11. [CrossRef]

Zhu, Qinghua, Ernest A. Lowe, Yuan-an Wei, and Donald Barnes. 2008. Industrial Symbiosis in China: A Case Study of the Guitang Group. Journal of Industrial Ecology 11: 31-42. [CrossRef]

Zhu, Li, Jianren Zhou, Zhaojie Cui, and Lei Liu. 2010. A method for controlling enterprises access to an eco-industrial park. Science of The Total Environment 408: 4817-25. [CrossRef] [PubMed]

(C) 2020 by the authors. Licensee MDPI, Basel, Switzerland. This article is an open access article distributed under the terms and conditions of the Creative Commons Attribution (CC BY) license (http://creativecommons.org/licenses/by/4.0/). 